\title{
Pulmonary blood flow and left ventricular volumes in transposition of the great arteries and intact ventricular septum ${ }^{1}$
}

\author{
John F. Keane, R. Curtis Ellison, Michael Rudd, and Alexander S. Nadas \\ From the Department of Cardiology, The Children's Hospital Medical Center, and the Department of \\ Pediatrics, Harvard Medical School, Boston, U.S.A.
}

Pulmonary blood flow and left ventricular volumes were determined angiographically from 33 studies on 30 patients (2I male, 9 female) with transposition of the great arteries and intact ventricular septum. Twelve of the studies were performed on infants under 2 months of age (median age 33 hours). The pulmonary blood flow in this group ranged from $I \cdot 3$ to 4.8 (mean, $3 \cdot 0$ ) $l . /$ min $/ \mathrm{m}^{2}$. There were $2 I$ studies on patients over 2 months of age (median age I6 months) with a pulmonary blood flow ranging from $3 \cdot 9$ to $I I \cdot 3$ (mean=6.4) l. $/ \mathrm{min} / \mathrm{m}^{2}$. This difference in mean pulmonary blood flow was statistically significant $(P<0.001)$.

Left ventricular end-diastolic volume ranged from 12 to 39 (mean, 31 ) $\mathrm{ml} / \mathrm{m}^{2}$ in those under 2 months of age and from 30 to 116 (mean, 70) $\mathrm{ml} / \mathrm{m}^{2}$ in those over this age. Left ventricular mass ranged from 15 to 35 (mean, 28) $\mathrm{g} / \mathrm{m}^{2}$ for those under 2 months of age and increased with increasing pulmonary blood flow. For the older group, it ranged from 32 to 150 (mean, 69) $\mathrm{g} / \mathrm{m}^{2}$ and showed a positive correlation with both pulmonary blood flow and left ventricular systolic pressure. The ejection fraction did not change with age and ranged from 0.57 to 0.85 (mean, 0.73 ) for the whole group.

In 8 patients, aged 9 months to 4 years (median age, $2 \frac{1}{4}$ years), oxygen consumption was measured; pulmonary blood flow as estimated by the Fick method in these ranged from 6.2 to 14.9 (mean, 10.4 ) $\mathrm{l} .1 \mathrm{~min} / \mathrm{m}^{2}$. This was appreciably higher than the figures 3.9 to 8.7 (mean, 6.5) $\mathrm{l} . / \mathrm{min} / \mathrm{m}^{2}$ obtained by the angiographic method during the same study.

Measurement of pulmonary blood flow using the Fick principle when the arteriovenous oxygen difference is small is felt to be inaccurate (Mesel, 1970). In patients with transposition of the great arteries, particularly those with intact ventricular septum, estimation of pulmonary blood flow by the Fick method is suspect of rendering erroneously high values (Burchell, 1966). In this group of patients angiograms of the left ventricle and the pulmonary ventricle, have been used as an alternative method for measuring pulmonary blood flow (Graham et al., 1971a).

In the present study, we have used biplane angiography to determine pulmonary blood flow, left ventricular mass, and left ventricular ejection fraction in 33 studies on 30 patients with transposition

Received 6 November 1972.

1 Supported in part by grants from the National Heart and Lung Institutes of the National Institutes of Health, Bethesda, Maryland. of the great arteries and intact ventricular septum. Specifically, we have sought to determine differences in pulmonary blood flow during and after the neonatal period, to compare pulmonary blood flow derived from the Fick method with that obtained from left ventricular angiograms, and to speculate on the determinants of pulmonary blood flow in patients with transposition of the great arteries and intact ventricular septum. In addition, we have analysed the characteristics of left ventricular function in these patients.

\section{Subjects and methods}

We have reviewed the cardiac catheterization data obtained from patients with transposition of the great arteries and intact ventricular septum studied at the Children's Hospital Medical Center, Boston. Only those studies that permitted accurate angiographic analysis of left ventricular volumes were selected. Between I965 and I972, 33 such studies were available, performed on 30 
patients (2I male, 9 female). Twelve of these catheterizations were carried out on very cyanotic infants less than 2 months of age (median age, 33 hours). The remaining 2I studies were undertaken at ages ranging from 7 months to 4 years 4 months (median age, 16 months). The latter studies were undertaken primarily in patients being evaluated for surgical repair by the Mustard procedure. Fortuitously, there were no studies between 3 and 6 months of age in this series of patients. A very small ventricular septal defect was present in 3 of the patients and a minimally persistent ductus arteriosus in another. On the basis of oxygen saturation, pressure, and angiographic data, it was felt that these additional lesions were haemodynamically insignificant and these patients were thus not excluded. Balloon septostomy was performed just before or shortly after the angiogram during the catheterization in all those less than 2 months of age. Of the older group of patients, 16 had had a previous surgical atrial septostomy and 5 had previously undergone balloon atrial septostomy only. The pulmonary artery was entered during 13 of the studies, all in the older age group.

Angiograms were recorded by biplane equipment (3I on $35 \mathrm{~mm}$ cine film, 2 on full-size cut film), the site of injection of contrast material being either the left atrium or the left ventricle. Left ventricular volumes were then calculated using the method previously described from this institution (Tyrell et al., 1970) and using the regression equation for infancy and childhood as determined by Graham et al. (197Ib).

Oxygen consumption was determined in 8 patients aged 9 months to 4 years using a Kipp-Zonen diapherometer (Stocker et al., 1972), and pulmonary blood flow using the Fick method was calculated and compared with angio-derived values obtained at similar heart rates. In 7 of these children the pulmonary artery was entered during the study while in the eighth patient, the left ventricular saturation of 88 per cent was used as an adequately mixed venous sample. A pulmonary vein was entered in all.

Systemic output was determined by the Fick principle using simultaneous saturations from the superior vena cava and a systemic artery. Saturations were measured on an American Optical Company standard oximeter.

\section{Results}

Pulmonary blood flow measured angiographically in the 12 patients less than 2 months of age ranged from I. 3 to 4.8 (mean, 3.0 ) $1 . / \mathrm{min} / \mathrm{m}^{2}$. For 8 of these infants studied in oxygen, the mean value was 2.8 $1 . / \mathrm{min} / \mathrm{m}^{2}$, compared to $3.4 \mathrm{l} . / \mathrm{min} / \mathrm{m}^{2}$ for the remaining 4 patients studied in room air. In the 21 studies performed over 2 months of age all in room air, pulmonary blood flow ranged from 3.9 to $11 \cdot 3$ $1 . / \mathrm{min} / \mathrm{m}^{2}$, and the mean value of $6.41 . / \mathrm{min} / \mathrm{m}^{2}$ was significantly higher $(P<0.001)$ when compared with the mean value of those under 2 months (Fig. I). There was no relation between pulmonary blood flow and arterial oxygen saturation.

For the entire group, left ventricular end-diastolic

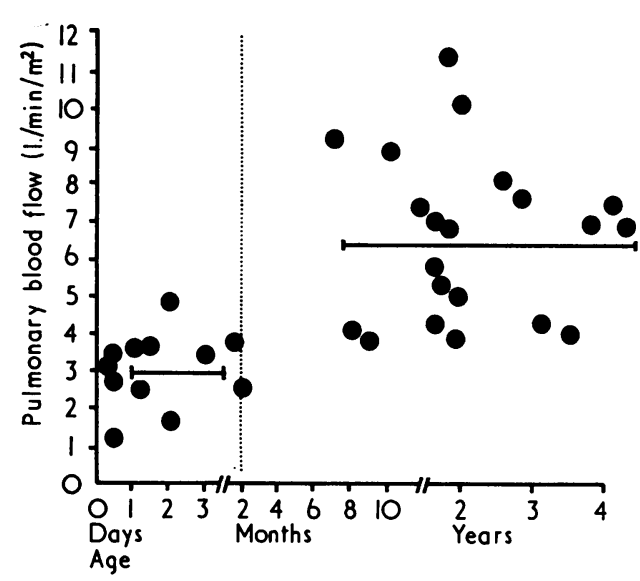

FIG. I Pulmonary blood flow, by angiographic analysis, related to age. The mean value for those under 2 months was $3.0 \mathrm{l} . / \mathrm{min} / \mathrm{m}^{2}$ and was 6.4 l. $/ \mathrm{min} / \mathrm{m}^{2}$ for those over this age.

volume increased with age (Fig. 2) and with pulmonary blood flow (Fig. 3). In the newborns, it ranged from 12 to 39 (mean, $3 \mathrm{I}$ ) $\mathrm{ml} / \mathrm{m}^{2}$ and from 30 to 116 (mean, 70 ) $\mathrm{ml} / \mathrm{m}^{2}$ for those in the older age group. Left ventricular mass increased with increasing pulmonary blood flow for the whole group (Fig. 4). The left ventricular mass was unrelated to pressure in those under 2 months but increased with increasing pressure in the older children. In patients under 2 months of age, the left

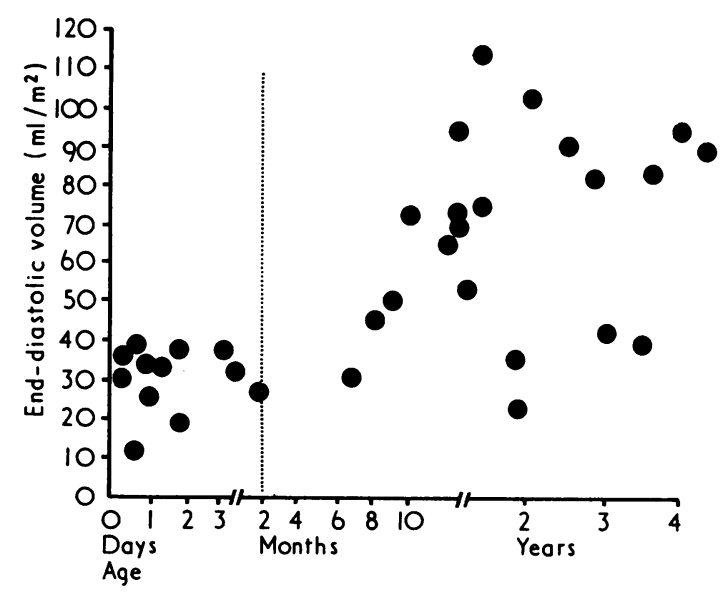

FIG. 2 Left ventricular end-diastolic volume, by angiographic analysis, related to age. Higher values were found in the older patients. 


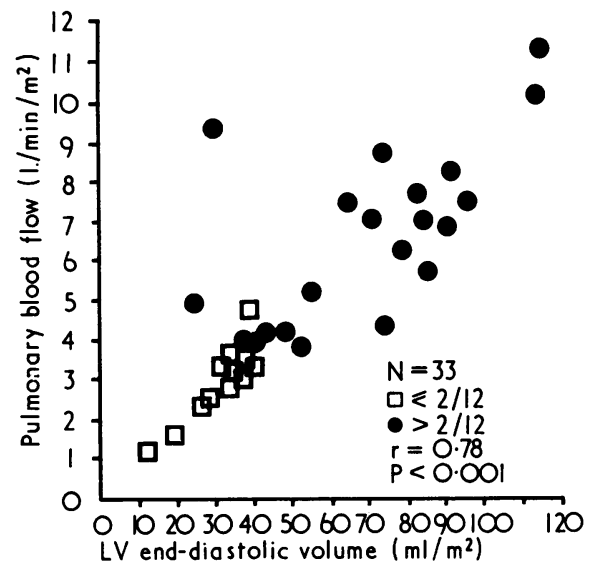

FIG. 3 Left ventricular end-diastolic volume showed a significant correlation with pulmonary blood flow, both determined angiographically.

ventricular mass ranged from is to 35 (mean, 28) $\mathrm{g} / \mathrm{m}^{2}$, while in those over this age it ranged from 32 to 150 (mean, 69) $\mathrm{g} / \mathrm{m}^{2}$. The highest value of 150 $\mathrm{g} / \mathrm{m}^{2}$ was measured in a patient, 4 years and 4 months of age, whose pulmonary arterial pressure was at systemic level. The left ventricular ejection fraction was unrelated to age and ranged from 0.57 to 0.85 (mean, 0.73 ). There was no relation between the ejection fraction and the arterial oxygen saturation either.

In the 13 patients in whom the pulmonary artery was entered, the gradient across the left ventricular

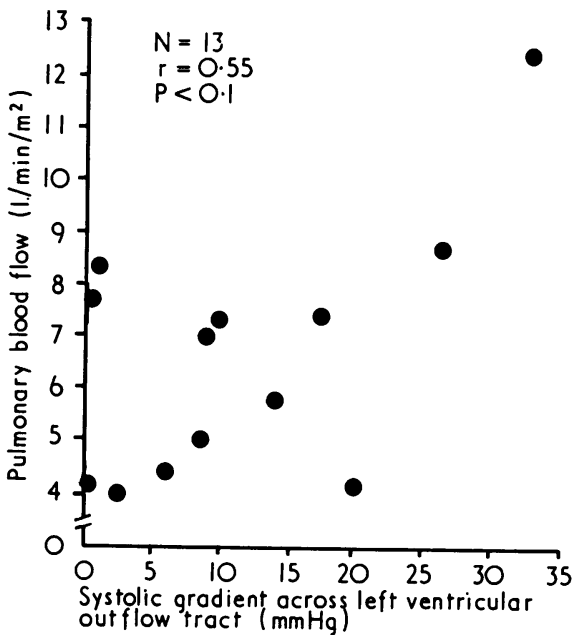

FI G. 5 No significant relation was found between the systolic gradient across the left ventricular outflow tract and the angiographically derived pulmonary blood flow.

outflow tract was measured. In 7 of these children, the gradient was less than $10 \mathrm{mmHg}$, while in the remaining 6 it ranged from to to 33 (mean, 20) mmHg. The relation between this gradient and the angio-determined pulmonary blood flow was not statistically significant (Fig. 5).

The calculated pulmonary and systemic blood flows and arterial oxygen saturations obtained in

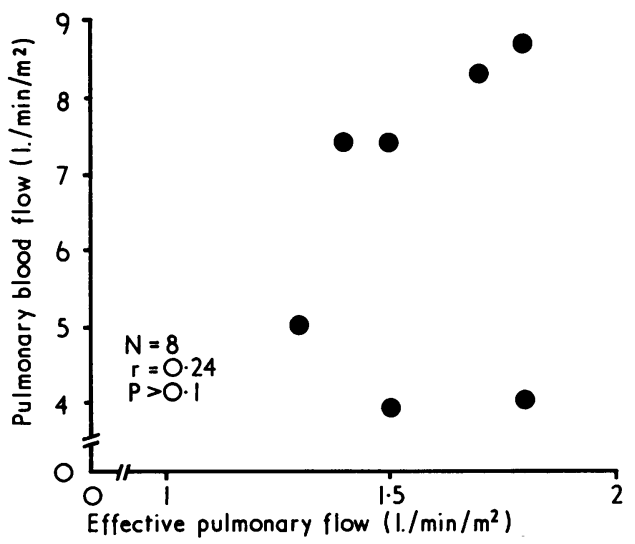

FIG. 6 The effective pulmonary blood flow, derived by the Fick method, did not correlate significantly with the angiographically derived pulmonary blood flow.
FIG. 4 Left ventricular mass showed a significant correlation with pulmonary blood flow. 
TABLE Data obtained from patients with measured oxygen consumption

\begin{tabular}{|c|c|c|c|c|c|c|c|}
\hline Case No. & Age (yr) & $\begin{array}{l}Q p(\text { Fick }) \\
\left(l . / \min / \mathrm{m}^{2}\right)\end{array}$ & $\begin{array}{l}Q p(\text { angio }) \\
\left(l . / \mathrm{min} / \mathrm{m}^{2}\right)\end{array}$ & $\begin{array}{l}\text { Qs (Fick) } \\
\left(\text { l. } / \min / \mathrm{m}^{2}\right)\end{array}$ & $\frac{Q p(\text { Fick })}{Q s(\text { Fick })}$ & $\frac{Q p(\text { angio })}{Q s(\text { Fick })}$ & $S A$ sat. $\%$ \\
\hline $\mathbf{I}$ & 9/12 & 8.5 & 3.9 & 2.9 & $3 \cdot 0 / 1$ & $I \cdot 3 / I$ & 63 \\
\hline 2 & $10 / 12$ & II 5 & $8 \cdot 7$ & $3 \cdot 3$ & $3.5 / 1$ & $2 \cdot 6 / 1$ & 73 \\
\hline 3 & $12 / 12$ & $13 \cdot 2$ & $7 \cdot 4$ & $4 \cdot 8$ & $2 \cdot 7 / 1$ & $I \cdot 5 / 1$ & 52 \\
\hline 4 & I II $/ 12$ & $7 \cdot 8$ & 5.0 & 5.6 & $I \cdot 4 / I$ & $0.9 / 1$ & 55 \\
\hline $\begin{array}{l}5 \\
5\end{array}$ & $27 / 12$ & $8 \cdot 4$ & $8 \cdot 3$ & 4.5 & $\mathrm{I} \cdot 8 / \mathrm{I}$ & $I \cdot 8 / I$ & 72 \\
\hline 6 & $36 / 12$ & $6 \cdot 2$ & 4.0 & $8 \cdot 1$ & $0.8 / 1$ & $0.5 / 1$ & 65 \\
\hline 7 & $38 / 12$ & 14.9 & $7 \cdot 0$ & $4 \cdot 3$ & $3.5 / 1$ & $I \cdot 6 / 1$ & 75 \\
\hline 8 & $4 \mathrm{I} / 12$ & 13.0 & $7 \cdot 4$ & 4.0 & $3 \cdot 2 / 1$ & $I \cdot 9 / I$ & 70 \\
\hline & Mean & 10.4 & 6.5 & $4 \cdot 6$ & $2.5 / 1$ & $1 \cdot 5 / 1$ & \\
\hline
\end{tabular}

Angio, angiographic analysis; Qp, pulmonary blood flow; Qs, systemic blood flow; SA sat. \%, systemic arterial oxygen saturation.

the group of 8 patients in whom oxygen consumption was measured are illustrated in the Table. Pulmonary blood flow as calculated by the Fick method was considerably higher than that obtained by angio analysis in all but one (mean, 10.4 $1 . / \mathrm{min} / \mathrm{m}^{2}$, compared to mean, $6.51 . / \mathrm{min} / \mathrm{m}^{2}$ ). A similar relation was noted in an additional 6 patients aged 6 months to 4 years, in whom oxygen consumption values were assumed (Rudolph and Cayler, 1958). The pulmonary to systemic flow ratio ( $\mathrm{p} / \mathrm{Qs})$, where both were measured by Fick, ranged from 0.8 to $3.5 / 1$ (mean, 2.5/1), whereas the Qp/Qs, where pulmonary blood flow was determined by angio analysis and systemic flow by Fick, ranged from 0.5 to $2 \cdot 6 / 1$ (mean, $1 \cdot 5 / 1$ ). In 2 patients (Cases 4 and 6) where pulmonary blood flow was measured

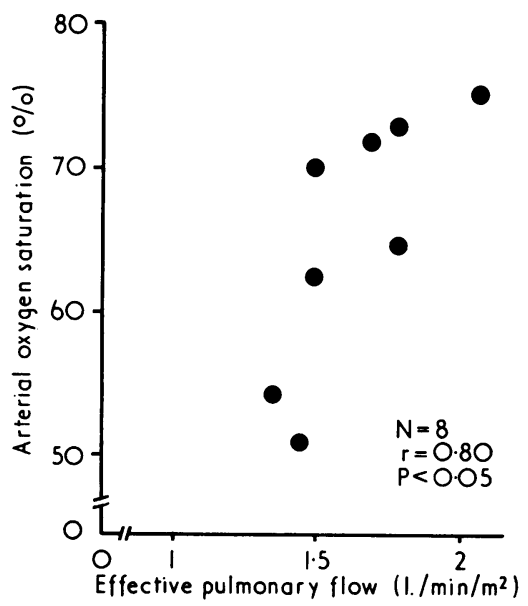

FIG. 7 A significant relation was found between the Fick-determined effective pulmonary blood flow and the arterial oxygen saturation. angiographically, the $\mathrm{Qp} / \mathrm{Qs}$ ratio was 0.9 and $0.5 / \mathrm{r}$, with arterial oxygen saturations of 55 and 65 per cent, respectively. A Qp/Qs ratio of less than I was observed in another 4 patients in whom oxygen consumption values were assumed. In the group of 8 patients, there was no relation between pulmonary blood flow and left ventricular pressure, between pulmonary blood flow and left atrial pressure, or between pulmonary blood flow and effective pulmonary blood flow (Fig. 6). Effective pulmonary blood flow ranged from $1 \cdot 3$ to 2.6 (mean, $I \cdot 7$ ) $1 . / \mathrm{min} / \mathrm{m}^{2}$. Arterial oxygen saturation increased with increasing effective pulmonary blood flow (Fig. 7) and with increasing oxygen carrying capacity (Fig. 8).

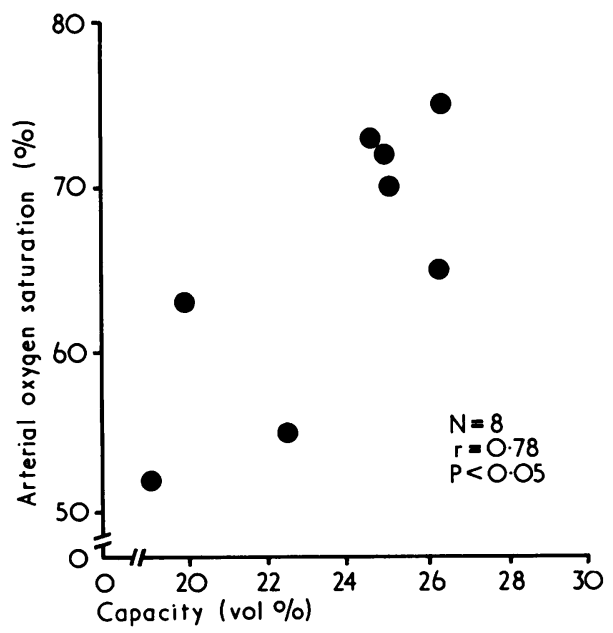

FIG. 8 Oxygen carrying capacity showed a significant correlation with arterial oxygen saturation. 


\section{Discussion}

Systemic cardiac output in normal newborn infants has been measured previously by the dye-dilution method. Gessner et al. (1965) obtained a mean value of $3.901 . / \mathrm{min} / \mathrm{m}^{2}$ (range 3.15 to $4.651 . / \mathrm{min} / \mathrm{m}^{2}$ ) in a study on 14 newborns ranging in age from 0 to 20 hours; Arcilla et al. (1967) calculated a mean left ventricular output of $3.351 . / \mathrm{min} / \mathrm{m}^{2}$ (range 3.08 to $3.621 . / \mathrm{min} / \mathrm{m}^{2}$ ) in a study of 45 infants ranging from 2 to 24 hours of age and Emmanouilides et al. (I970) obtained a mean value of $4.071 . / \mathrm{min} / \mathrm{m}^{2}$ (range 3.80 to $4.341 . / \mathrm{min} / \mathrm{m}^{2}$ ) during observations on 23 babies ranging in age from 6 to 35 hours. Similar values for effective pulmonary capillary flow were obtained by Brady and Rigatto (197I), using a plethysmographic and nitrous oxide technique, in 24 babies up to 14 days of age. One may assume from these studies that systemic and pulmonary blood flows in normal newborns, without significant shunts, vary between $3-41 . / \mathrm{min} / \mathrm{m}^{2}$.

Estimation of left ventricular output by angiographic analysis has been shown to be a valid technique (Dodge, Hay, and Sandler, I962; Graham et $a l$. , 1970). In patients with transposition of the great arteries and intact ventricular septum, this measurement reflects pulmonary blood flow, since surgical experience suggests that bronchial collateral flow in these patients is minimal (Mair et al., 197I).

Our findings indicate that pulmonary blood flow in patients with transposition of the great arteries and intact ventricular septum is within the normal range in the first 2 months of life. In older infants, values approximately twice this level were found, presumably due to a progressive decrease in pulmonary vascular resistance.

As expected, the left ventricular end-diastolic volume and calculated left ventricular mass increased with age and with pulmonary blood flow. In the older infants and children, left ventricular mass also increased with left ventricular systolic pressure. This suggests that both volume work and pressure work are important in determining the left ventricular mass. Though the numbers are few, there seemed to be a tendency for a greater increase in left ventricular mass with an increase in pressure than with an increase in volume load in the left ventricle.

The ejection fraction was within normal limits in all patients and appeared to be unrelated to the pulmonary blood flow or to the arterial oxygen saturation. Thus, in our patients, the low arterial oxygen saturation in the coronary arteries did not appear to cause impairment of left ventricular function, as reflected in the ejection fraction. Our observations regarding the pulmonary blood flow and left ventricular volumes are similar to the findings of Graham et al. (1971a) from their study of 21 patients with transposition of the great arteries with intact ventricular septum. By contrast, our data relating to left ventricular mass are lower than the values for normals as reported by Graham et al. (I97Ib) probably because left ventricular pressure in transposition of the great arteries and intact ventricular septum is commonly below the systemic level.

Use of the Fick principle to calculate blood flow when arteriovenous oxygen saturation difference is small is thought to be unreliable. Mesel (1970) has shown, in experimental studies using a electromagnetic flow transducer, that the Fick method usually much overestimated pulmonary blood flow when pulmonary artery saturation exceeded 85 per cent. Oxygen saturation in the pulmonary artery of patients with transposition of the great arteries and intact ventricular septum is commonly well above this level. In our group of 8 patients in whom oxygen consumption was measured, and in an additional 6 in whom it was assumed, the Fick-determined pulmonary blood flow exceeded the angio-derived value considerably in all but one.

It is worth noting, and somewhat surprising, that in 6 patients over 2 months of age with transposition of the great arteries and intact ventricular septum, the $Q p / Q s$ ratio was less than $I$. The mean values of arterial oxygen saturation and capacity were 59 and 23 vol. per cent, respectively, in this group, being similar to the respective mean values of 62 and $24 \mathrm{vol}$. per cent for the other 15 patients over 2 months of age whose $Q p / Q s$ ratios exceeded $I$. The mean effective pulmonary blood flow in this group of 6 patients was $\mathrm{r} \cdot 8 \mathrm{l} . / \mathrm{min} / \mathrm{m}^{2}$ and it was $\mathrm{I} \cdot 7$ $1 . / \mathrm{min} / \mathrm{m}^{2}$ for the other children.

The systemic arterial saturation did not prove to be a reliable index of the magnitude of pulmonary blood flow. Confirmation of this was seen in Case 6 (Table) where the pulmonary blood flow by angiographic analysis was only $4.01 . / \mathrm{min} / \mathrm{m}^{2}$ yet the systemic arterial saturation was an acceptable 65 per cent. Case 3, by contrast, had a pulmonary blood flow of $7 \cdot 4 \mathrm{l} / \mathrm{min} / \mathrm{m}^{2}$ with an arterial saturation of only 52 per cent. On the other hand, systemic saturation was found to be directly proportional to effective pulmonary flow, representing the degree of mixing between the two circuits, and also to haemoglobin level. Similar results have recently been described by Mair et al. (I97I) in a study of patients with transposition of the great arteries and ventricular septal defect. It is of interest that the mean effective pulmonary blood flow reported in that study is similar to that found in our group.

The determinants of pulmonary blood flow in 
transposition of the great arteries and intact ventricular septum are unknown. In normal subjects without shunts, the pulmonary blood flow equals systemic blood flow. The chemo- and baro-receptors in the circulation demand a certain magnitude of systemic flow which would then be passed on passively to the pulmonary circuit. In patients with large shunts without transposition, the pulmonary blood flow is determined by the relation between the total systemic and pulmonary resistances and by the size of the shunt orifice. In individuals with transposition of the great arteries and intact ventricular septum the presence of a bidirectional shunt of equal magnitude between the two circuits is necessary for survival. The size of the pulmonary blood flow is independent of the systemic output, and may be controlled entirely by the level of the total pulmonary resistance, rather than the resistance ratio. It is possible that an increase in systemic blood flow could lead to an increase in the right atrial pressure, which would then lead to an increase in left atrial and thus left ventricular filling pressure: this could, by Starling's law, lead to an increase of pulmonary flow. However, we did not find a correlation between the level of left atrial pressure and pulmonary blood flow, nor between the systemic blood flow and pulmonary blood flow in our patients. The level of systemic arterial saturation also failed to show a close correlation with pulmonary blood flow, suggesting that neurohumeral mechanisms initiated by low saturation are not important determinants of the pulmonary flow. Thus, the possible systemic determinants of the pulmonary blood flow remain obscure.

\section{References}

Arcilla, R. A., Oh, W., Wallgren, G., Hanson, J. S., Gessner, I. H., and Lind, J. (I967). Quantative studies of the human neonatal circulation. II. Hemodynamic findings in early and late clamping of the umbilical cord. Acta Paediatrica Scandinavica, 56, Suppl. 179, 23.
Brady, J. P., and Rigatto, H. (197I). Pulmonary capillary flow in the newborn infant: a new method using the plethysmograph and nitrous oxide. Pediatrics, 48, 207.

Burchell, H. B. (1966). Some hemodynamic problems in transposition of the great vessels. Circulation, 33, 181.

Dodge, H. T., Hay, R. E., and Sandler, H. (1962). An angiocardiographic method for directly determining left ventricular stroke volume in man. Circulation Research, II, 739.

Emmanouilides, G. C., Moss, A. J., Monset-Couchard, M., Marcano, B. A., and Rzeznic, B. (1970). Cardiac output in newborn infants. Biologia neonatorum, $15,186$.

Gessner, I., Krovetz, L. J., Benson, R. W., Prystowsky, H., Stenger, V., and Eitzman, D. V. (1965). Hemodynamic adaptations in the newborn infant. Pediatrics, 36, 752.

Graham, T. P., Jr., Jarmakani, J. M., Canent, R. V., Jr., and Jewett, P. H. (1971a). Quantification of left heart volume and systolic output in transposition of the great arteries. Circulation, 44, 899.

Graham, T. P., Jr., Jarmakani, J. M., Canent, R. V., Jr., and Morrow, M. N. (197Ib). Left heart volume estimation in infancy and childhood. Circulation, 43, 895.

Graham, T. P., Jr., Lewis, B. W., Jarmakani, M. M., Canent, R. V., Jr., and Capp, M. P. (1970). Left heart volume and mass quantification in children with left ventricular pressure overload. Circulation, 41, 203.

Mair, D. D., Ritter, D. G., Ongley, P. A., and Helmholz, H. F. (1971). Hemodynamics and evaluation for surgery of patients with complete transposition of the great arteries and ventricular septal defect. American fournal of Cardiology, 28, 632 .

Mesel, E. (1970). Direct measurement of intracardiac blood flow in dogs with experimental ventricular septal defects. Circulation Research, 27, 1033.

Rudolph, A. M., and Cayler, G. G. (1958). Cardiac catheterization in infants and children. Pediatric Clinics of North America, 5, 907.

Stocker, F. P., Wilkoff, W., Miettinen, O. S., and Nadas, A. S. (1972). Oxygen consumption in infants with heart disease. Fournal of Pediatrics, 80, 43.

Tyrell, M. J., Ellison, R. C., Hugenholtz, P. G., and Nadas, A. S. (1970). Correlation of degree of left ventricular volume overload with clinical course in aortic and mitral regurgitation. British Heart fournal, 32, 683.

Requests for reprints to Dr. John F. Keane, Department of Cardiology, The Children's Hospital Medical Center, 300 Longwood Avenue, Boston, Massachusetts 02II5, U.S.A. 